\title{
A 2D model of a gliding arc discharge for $\mathrm{CO}_{2}$ conversion
}

Cite as: AIP Conference Proceedings 2075, 060008 (2019); https://doi.org/10.1063/1.5091186

Published Online: 26 February 2019

Ts. Paunska, G. Trenchev, A. Bogaerts, and St. Kolev

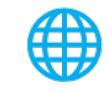

\section{Conference Proceedings}

Get $30 \%$ off all print proceedings!

\section{Enter Promotion Code PDF30 at checkout}

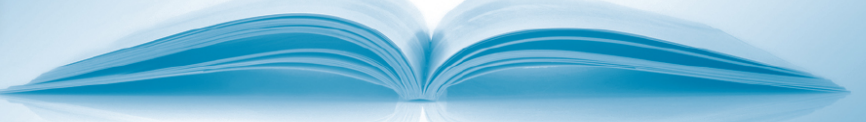




\title{
A 2D Model of a Gliding Arc Discharge for $\mathrm{CO}_{2}$ Conversion
}

\author{
Ts. Paunska ${ }^{1, \text { a) }}$, G. Trenchev ${ }^{2}$, A. Bogaerts ${ }^{2}$ and St. Kolev ${ }^{1}$ \\ ${ }^{I}$ Faculty of Physics, Sofia University, 5 J. Bourcheir Blvd., BG-1164 Sofia, Bulgaria \\ ${ }^{2}$ Research group PLASMANT, Department of Chemistry, University of Antwerp, Universiteitsplein 1, \\ B-2610 Antwerp, Belgium \\ ${ }^{\text {a)} C o r r e s p o n d i n g ~ a u t h o r: ~ c w a l c h e w @ p h y s . u n i-s o f i a . b g ~}$
}

\begin{abstract}
The study presents a 2D fluid plasma model of a gliding arc discharge for dissociation of $\mathrm{CO}_{2}$ which allows its subsequent conversion into value-added chemicals. The model is based on the balance equations of charged and neutral particles, the electron energy balance equation, the gas thermal balance equation and the current continuity equation. By choosing the modeling domain to be the plane perpendicular to the arc current, the numerical calculations are significantly simplified. Thus, the model allows us to explore the influence of the gas instabilities (turbulences) on the energy efficiency of $\mathrm{CO}_{2}$ conversion. This paper presents results for plasma parameters at different values of the effective turbulent thermal conductivity leading to enhanced energy transport.
\end{abstract}

\section{INTRODUCTION}

The gliding arc discharge (GAD) is one of the most attractive plasma sources for $\mathrm{CO}_{2}$ dissociation [1-4]. The topic is extremely up to date due to the global warming and its associated consequences. The main efforts of the optimization of this type of plasma sources are aimed at increasing the conversion and energy efficiency [2-5]. The numerical modeling makes a significant contribution in this direction.

Because of the complicated kinetic of $\mathrm{CO}_{2}$ and the need of significant computational resources, the models of GAD with detailed plasma chemistry are only few [4-7]. Valuable conclusions follow even from the 0-dimensional model in [4]. It is well known that the $\mathrm{CO}_{2}$ dissociation is significant when the highly excited vibrational levels of the asymmetric mode are populated. Selection of conditions to maintain appropriate form of the vibrational distribution function is a way to increase the conversion. The model predicts that the gas temperature close to 1000 $\mathrm{K}$ and greater power density improve the conversion and energy efficiency. The other important option for optimization is to remove the $\mathrm{O}$ atoms from the systems by chemical trapping with $\mathrm{H}$ atoms. This would prevent $\mathrm{CO}$ and $\mathrm{O}$ dissociated particles from recovering to $\mathrm{CO}_{2}$ through the reverse reaction. One of the disadvantages of the GAD is that the fraction of the treated gas is limited. The 1D model in Ref. [6] shows that only at the distance less than $0.5 \mathrm{~mm}$ from the center of the arc the $\mathrm{CO}_{2}$ dissociation is significant. It is clear that another way to improve the $\mathrm{CO}_{2}$ conversion would be to enhance the fraction of the gas which can be treated by the arc. A 2D model of Wang et. al. [5] demonstrates the potential of two ways to increase the volume of the treated gas. One of them is to increase the gas velocity and hence the relative velocity of the arc to the gas (in experiments it was observed that the arc gliding velocity can be slightly lower than the gas velocity). This difference affects not only the amount of gas being treated but also its cooling. Other possibility is to use natural phenomena observed at larger gas flow, which are known as "back-breakdown events". As a result a new discharge channel is formed. Increasing the number of this phenomena the conversion of $\mathrm{CO}_{2}$ and energy-efficiency are improved.

The study presented here is a 2D fluid plasma model which is in scope of the numerical investigation of the GAD [1-7]. The purpose of the simulations is to investigate the impact of gas velocity and turbulence on the energy efficiency of $\mathrm{CO}_{2}$ dissociation of the discharge. The modeling domain is in plane perpendicular to the arc current, which means that we neglect effects related with the arc extension in the other, non-simulated direction. The latter approximation is reasonable when the particle and energy transport processes are negligible compared to the

10th Jubilee International Conference of the Balkan Physical Union

AIP Conf. Proc. 2075, 060008-1-060008-4; https://doi.org/10.1063/1.5091186 Published by AIP Publishing. 978-0-7354-1803-5/ $\$ 30.00$ 
processes in direction transverse to the arc current like for example when the turbulent heat transport is dominant. This configuration can give the possibility for flexible changes of many parameters. In this paper the influence of the turbulence on plasma properties are investigated. The results for energy-efficiency of $\mathrm{CO}_{2}$ are obtained at different values of turbulent thermal conductivity.

\section{DESCRIPTION OF THE MODEL}

The 2D fluid plasma model presented here is structured as the model in Ref. [8]. The set of equations includes the balance equations of charged and neutral particles, the electron energy balance equation, the gas thermal balance equation and the current continuity equation. The quasineutral modeling approach is used [8] and the ambipolar electric field is not included in the particle fluxes in an apparent form. The modeling domain is a cross section of the arc channel, i.e. the plane perpendicular of the arc current. Because of the symmetry only the half part of cross section is modeled.

The $\mathrm{CO}_{2}$ chemistry is taken into account as in Ref. [6]. The particles in the model are the neutral ground species $\left(\mathrm{CO}_{2}, \mathrm{CO}, \mathrm{C}, \mathrm{O}_{2}, \mathrm{O}\right)$, the charged species $\left(\mathrm{CO}_{2}^{+}, \mathrm{O}_{2}^{+}, \mathrm{CO}_{3}^{-}, \mathrm{O}_{2}^{-}, \mathrm{O}^{-}, \mathrm{e}^{-}\right)$and the neutral excited species $\left(\mathrm{CO}_{2}\left(\mathrm{v}_{\mathrm{a}}\right)\right.$, $\left.\mathrm{CO}_{2}\left(\mathrm{v}_{\mathrm{b}}\right), \mathrm{CO}_{2}\left(\mathrm{v}_{\mathrm{c}}\right), \mathrm{CO}_{2}\left(\mathrm{v}_{\mathrm{d}}\right), \mathrm{CO}_{2}\left(\mathrm{v}_{1}-\mathrm{v}_{7}\right), \mathrm{CO}_{2}\left(\mathrm{v}_{8}-\mathrm{v}_{14}\right), \mathrm{CO}_{2}\left(\mathrm{v}_{15}-\mathrm{v}_{21}\right), \mathrm{CO}_{2}\left(\mathrm{e}_{1}\right)\right)$. All symmetric mode vibrational levels $\mathrm{CO}_{2}\left(\mathrm{v}_{\mathrm{a}}, \mathrm{v}_{\mathrm{b}}, \mathrm{v}_{\mathrm{c}}, \mathrm{v}_{\mathrm{d}}\right)$ are considered separately, while asymmetric mode vibrational levels $\mathrm{CO}_{2}\left(\mathrm{v}_{1}-\mathrm{v}_{21}\right)$, are lumped of 3 groups. It has been observed that this simplification does not have a significant impact on the vibrational distribution function [6].

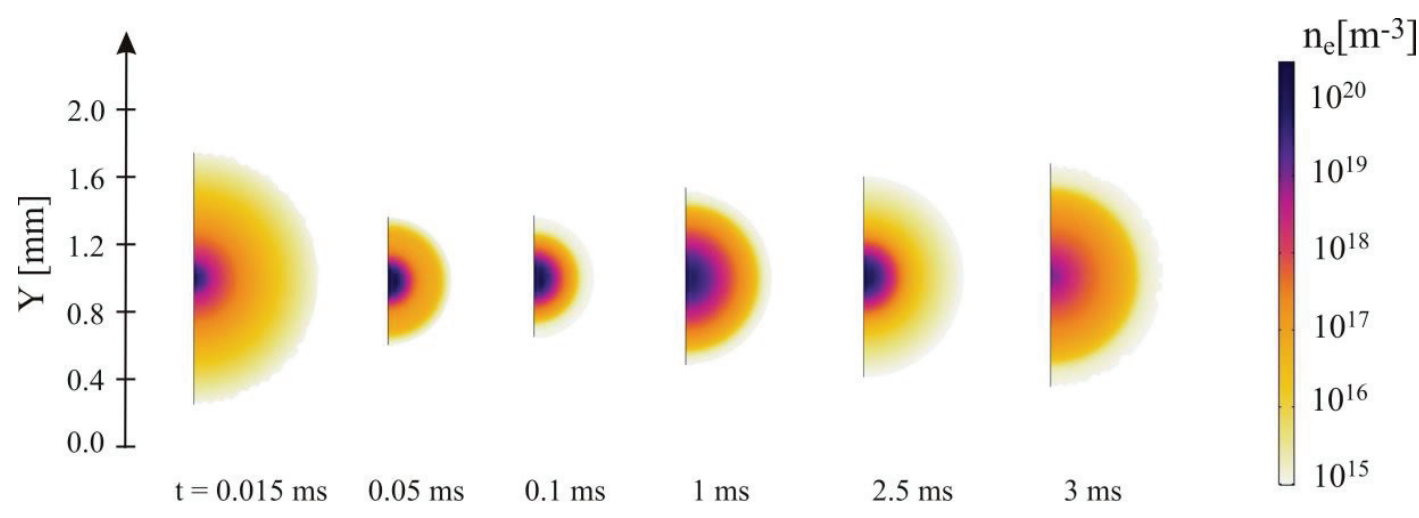

FIGURE 1. 2D plots of the electron density at different moments of time for $k_{\mathrm{t}}=0$. The cutout range is selected to show a density distribution of $n_{\mathrm{e}}>10^{15} \mathrm{~m}^{-3}$.
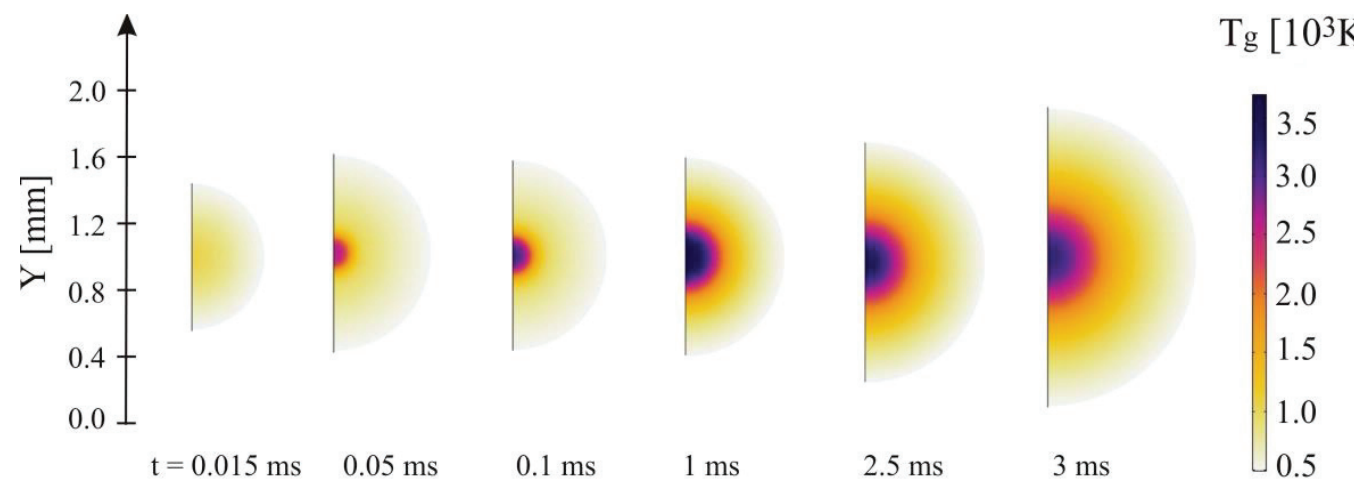

FIGURE 2. 2D plots of the gas temperature at different moments of time for $k_{\mathrm{t}}=0$. The cutout range is selected to show a gas temperature distribution of $T_{\mathrm{g}}>500 \mathrm{~K}$.

The simulation of the arc is started by introducing a heating term for a short time (about $15 \mu \mathrm{s}$ ) in the electron energy balance equation. The heating term is represented by a 2D Gaussian function, with narrow standard deviation 
$\left(3 \times 10^{-4} \mathrm{~m}\right)$. From this moment the arc is sustained by external power source with fixed arc current. In time, the electron density increases with two orders of magnitude (Fig. 1). In the model the external power source is switched off at time $2.5 \mathrm{~ms}$, and then the arc extinguishes gradually. The value is selected to correspond approximately to a speed of the $\operatorname{arc} \mathrm{v}_{\mathrm{arc}}=20 \mathrm{~m} / \mathrm{s}$ and moving path of $5 \mathrm{~cm}$. In the model the relative velocity of the arc with respect to the gas is not considered.

In this work the DC gliding arc discharge are considered. The current that is achieved in the plasma channel is 20 $\mathrm{mA}$ at fixed voltage of $6000 \mathrm{~V}$ and a ballast resistor with value $300 \mathrm{k} \Omega$.

The energy efficiency $\eta$ of the dissociation of $\mathrm{CO}_{2}$ is the most informative specification for the application. It is determined by the ratio of the dissociation enthalpy $(\Delta H=2.9 \mathrm{eV} /$ molecule $)$ to the actual energy cost of one $\mathrm{CO}$ molecule $\left(E_{\mathrm{n}}\right)$ produced in a plasma system [1] i.e. $\eta, \%=\left(\Delta H / E_{n}\right) \times 100$.

The effect of the turbulence on $\eta$ has been investigated in the present work. The different degrees of the turbulence are introduced by the parameter $k_{\mathrm{t}}$ which is an effective thermal conductivity due to turbulent transport, which is added to the gas own molecular thermal conductivity. The values of $k_{\mathrm{t}}$ studied are in the interval from 0 to $1 \mathrm{~W} / \mathrm{m} . \mathrm{K}$. They are chosen after the simulation based on the Shear Stress Transport Reynolds Averaged NavierStokes turbulent model [9] of the gas.

\section{RESULTS AND DISCUSSION}

The evolution of the gliding arc is shown in Fig. 1 and 2, with 2D distributions of the electron density $\left(n_{\mathrm{e}}\right)$ and the gas temperature $\left(T_{\mathrm{g}}\right)$ respectively. At the moment of contraction of the plasma channel (around $t=0.05 \mathrm{~ms}$ ), the density becomes in the order of $10^{20} \mathrm{~m}^{-3}$. After the arc switch-off time $(t=2.5 \mathrm{~ms})$ the maximum of the plasma density decreases rapidly. The gas heating is shifted over time and the gas temperature reaches a maximum of 3680 $\mathrm{K}$ around $t=1 \mathrm{~ms}$ (Fig. 3(a)).

The high gas temperatures around $3000 \mathrm{~K}$ even after the arc decay time indicates that the cooling of the gas is slow. This values of the $T_{\mathrm{g}}$ is in the range investigated in [4] with significant $\mathrm{CO}_{2}$ conversion but with reduced energy efficiency. In this condition the energy inserted in the plasma is not primarily used for dissociation. The energy efficiency without turbulence $\left(k_{\mathrm{t}}=0\right)$ from our simulation are comparatively low $12.06 \%$ (Fig. 3 (b)). By introducing a turbulent thermal conductivity, the energy efficiency is significantly reduced, for $k_{\mathrm{t}}>0.5$ it is about $4 \%$. This behavior can be explained with $\eta\left(T_{\mathrm{g}}\right)$ dependence (a curve similar to the inverted parabola) obtained in [4]. The presence of turbulence leads to faster cooling (Fig. 3(a)), the gas temperature decrease from $3680 \mathrm{~K}\left(k_{\mathrm{t}}=0\right)$ to $2000 \mathrm{~K}\left(k_{\mathrm{t}}=1\right)$ at the moment $t=1 \mathrm{~ms}$. The temperature values obtained from the model are in the minimum of the $\eta\left(T_{\mathrm{g}}\right)$ curve. In order to achieve optimal conditions for $\mathrm{CO}_{2}$ dissociation - high energy efficiency and conversion - it is necessary to introduce additional cooling mechanisms.

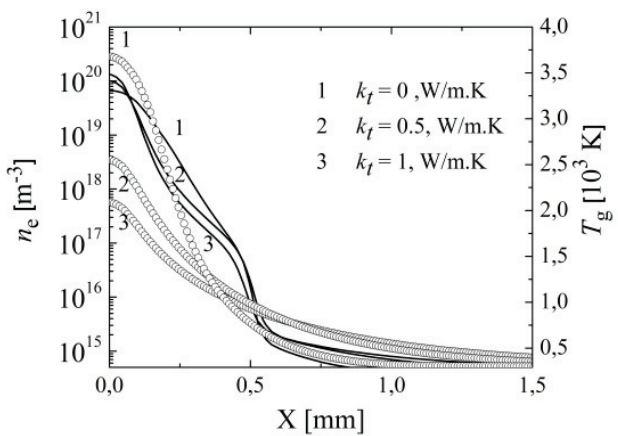

(a)

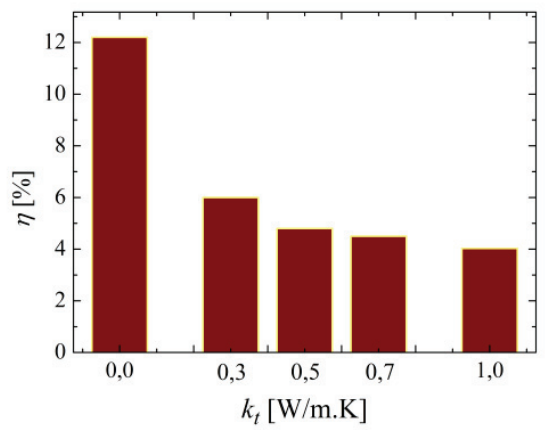

(b)

FIGURE 3. Radial distribution of the $n_{\mathrm{e}}$ (lines) and the $T_{\mathrm{g}}$ (symbols) at position $\mathrm{Y}=10 \mathrm{~mm}$ (the arc center) at $t=1 \mathrm{~ms}$ in (a) and the energy efficiency of the dissociation of $\mathrm{CO}_{2}$ in (b) at different values of the parameter $k_{\mathrm{t}}$. 
The total number of $\mathrm{CO}$ molecules per unit length of the arc, i.e. the integrated values of the $\mathrm{CO}$ density $\left\langle n_{\mathrm{CO}}\right\rangle$ over the cross section at different moment of time are shown on Fig. 4(a). They grow in time by forming a plateau after the arc extinguishing time. This is actually the amount of produced $\mathrm{CO}$. The presence of turbulence decreases $<n_{\mathrm{CO}}>$ about 1.3 times. The main reason for the reduction of the energy efficiency is the growth of the actual energy

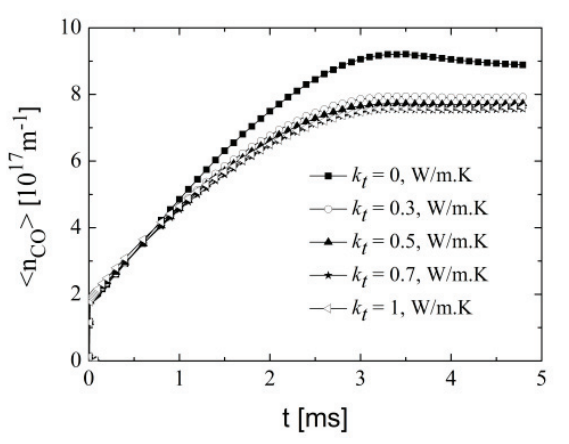

(a)

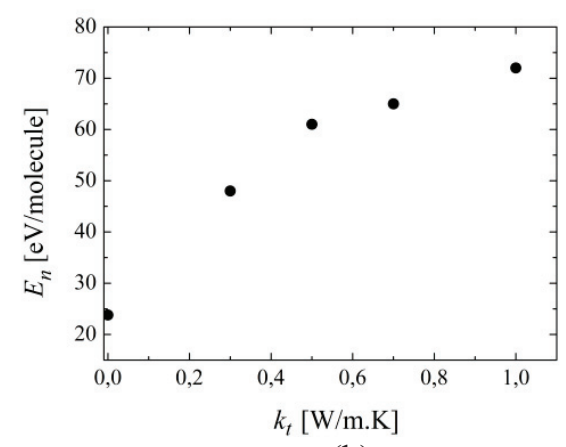

(b)

FIGURE 4. The spatially integrated values of the density of $\mathrm{CO}$ at different moments of time in (a) and the actual energy cost of one $\mathrm{CO}$ molecule produced in the plasma system at different values of parameter $k_{\mathrm{t}}$ in (b).

cost of one CO molecule produced in a plasma system. The $E_{\mathrm{n}}$ in our simulation (Fig. 4(b)) increases from 24 to 72 $[\mathrm{eV} / \mathrm{molecule}]$.

\section{CONCLUSIONS}

Simulations of the influence of the turbulent thermal conductivity on energy efficiency of the $\mathrm{CO}_{2}$ conversion in GAD have been performed. The results show that at discharge current about $20 \mathrm{~mA}$, the introduction of the turbulent thermal conductivity of $1 \mathrm{~W} / \mathrm{m} . \mathrm{K}$ is not sufficient to cool the gas to an optimal temperature for efficient $\mathrm{CO}_{2}$ dissociation. The influence of additional factors that could affect gas cooling, such as the relative velocity of the gas flow with respect to the arc, will be investigated after expanding the model.

\section{ACKNOWLEDGMENTS}

This work has been supported by Sofia University, grant no 80-10-180/26.04.2018.

\section{REFERENCES}

1. A. Fridman, Plasma Chemistry (Cambridge University Press, Cambridge, 2008), pp. 200-208.

2. T. Nunnally, K. Gutsol, A. Rabinovich, A. Fridman, A. Gutsol and A. Kemoun, J. Phys. D: Appl. Phys. 44, 274009 (2011).

3. A. Indarto, D. R. Yang, J. W. Choi, H. Lee, H. K. Song and J. Hazard. Mater 146, 309-315 (2007).

4. S. R. Sun, H. X. Wang, D. H. Mei, H. Tu and A. Bogaerts, Journal of $\mathrm{CO}_{2}$ Utilization 17, $220-234$ (2017).

5. W. Wang, D. Mei, X. Tu and A. Bogaerts, Chem. Engineering Journal 330, pp. 11-25 (2017).

6. W. Wang, A. Berthelot, St. Kolev, X. Tu and A. Bogaerts, Plasma Sources Sci. Technol. 25, 065012 (2016).

7. G. Trenchev, St. Kolev, W. Wang, M. Ramakers and A. Bogaerts, J. Phys. Chem. C 121, 24470-24479 (2017).

8. St. Kolev, S. Sun, G. Trenchev, W. Wang, H. Wang and A. Bogaerts, Plasma Processes and Polymers 14, 1600110 (2017).

9. F. R. Menter, M. Kuntz and R. Langtry, Turbulence Heat and Mass Transfer 4, (2003). 